\title{
A PRACTICAL APPROACH: NODE LOCALISATION ESTIMATION BASED ON RSSI FOR DISASTER CASES
}

\author{
Olaf Reich, Erik Hübner and Matthias Wagner \\ Frankfurt University of Applied Sciences \\ Department of Computer Science and Engineering \\ Nibelungenplatz, 1, D-60318 Frankfurt am Main, Germany
}

\begin{abstract}
An optimisation in localisation estimation is proposed based on received signal strength indicator (RSSI) measurements with a wireless mesh network (WMN) for urban environment. A mean deviation of $4.73 \%$ between measured and real distances was achieved. The WMN is based on ZigBee nodes for the usage in disaster scenarios without any infrastructure. The WMN is build up for basic navigation, internet of things (IoT) integration and sensor communication. Only six wireless mesh nodes are deployed under urban conditions and cover an area of 7.4 hectare. Noise cancelling is accomplished by an alpha-beta filter.
\end{abstract}

\section{KEYWORDS}

Nodes, Localisation, RSSI, Disaster, Wireless Sensor Network, ZigBee

\section{INTRODUCTION}

WMN have gained importance through applications in IoT and Industry 4.0. Especially the mesh topology has been integrated in wireless standards. These WMN offer a wide range of deployment possibilities. The usage in disaster situations without Global Position Satellite System (GPSS) support is investigated. While a WMN usually requires a thorough planning of positioning of the nodes this is not possible in case of a disaster. The basic idea for this study is using WMN to support navigation and positioning in a disaster or crisis situation. Disasters are causing damage to the infrastructure dependent on location and magnitude. Critical infrastructure comprised of among others power supply, central water supply and telecommunication networks (Jachs 2011). After a disaster took place the most important phase is the response phase (Altay \& Green 2006) focusing on the protection of the local population, the environment and saving lives by providing proper resources. Based on the destroyed infrastructure localisation and navigation are limited to the GPSS. The use of IoT devices is also critical in the context of a disaster scenario due to the destroyed communication and energy networks. Furthermore it is of great interest to provide different location-based services managing critical resources. Reliable localisation of IoT devices must be available even in absence of GPSS to ensure its viability in this kind of scenarios. The same applies to the use of WMN. GPSS is an ubiquitous technology and is used as state-of-the art navigation in many sectors. All main GPSS support the civilian sector but can be limited to a purely military use in serious cases. This history makes it obvious that outdoor positioning systems need to operate independently from position and location systems controlled by military decisions.

\subsection{Wireless Technology}

For the application scenarios the IEEE 802.15.4/ZigBee standard is an alternative to WiFi and Bluetooth. In a disaster case with destroyed infrastructure low-cost communication and low-power-consumption are imported properties (ZigBee Standards 2012). ZigBee supports two frequency bandwidths $2450 \mathrm{MHz} / 868 \mathrm{MHz}$ and a Peer-to-Peer architecture (Krauße \& Konrad 2014). 


\subsection{Localisation Methods}

There are two main concepts to estimate the position. The first is to determine the position and the velocity of a moving object, based on a known reference point. The second is the planning and controlling of the course from one location to another (Dreyer 2012). Various techniques are developed for both methods over the last centuries like angulation, lateration (Tariq et al. 2017), scene analysis (Lui et al. 2007), proximity-based location (Al-Ammar et al. 2014) as well as dead reckoning (Groves 2013). For angulation and lateration there are different techniques like Time of Arrival (TOA), Time Difference of Arrival (TDOA), Roundtrip Time of Flight (RTOF), Received Signal Phase Method (RSPH), Angle of Arrival (AOA) and Received Signal Strength (RSS) (Tariq et al. 2017). TOA, TDOA und RTOF need a very accurate clock within the nodes to measure the signal run time. Although very small atomic clocks already exist, these are on the one hand very expensive and on the other hand require a lot of energy. AOA and RSPH must be very precisely aligned or require several antennas but for a WMN in a disaster it is important that the nodes can be distributed quickly and easily. The RSSI, which is needed for RSS, is already integrated for most wireless technologies. The RSSI represents the signal power at the receiver and can be used to calculate the distance. This can be done by solving the equation from (Rappaport 2002) for $d$

$$
d=10 \frac{P_{0}-P_{d}}{10 \cdot n}-\lg (f)+3-\frac{32.44}{10 \cdot n}
$$

where $P_{d}$ is the received signal power in $\mathrm{dBm}$ at a specific distance $d, P_{0}$ is the signal power from the transceiver in $\mathrm{dBm}$ at distance zero at the antenna, $f$ is the signal frequency measured in $\mathrm{MHz}$ and $n$ is a variable depending on the environment.

\section{ENVIRONMENT}

The mesh network is constructed through fixed ZigBee nodes (FZN) which are $0.08 \mathrm{~m} \times 0.08 \mathrm{~m} \times 0.05 \mathrm{~m}$ small and weigh $0.15 \mathrm{~kg}$. All nodes are powered by two 1.5 Volt AA Mignon batteries. FZN are mounted on tripods at a height of $1.65 \mathrm{~m}$ and homogeneously distributed in the test area. The FZN use channel 16 with the middle signal frequency $f$ of $2430 \mathrm{MHz}$. Besides the RSSI value the Link Quality Indicator (LQI) is also used. It gives an estimation of the received signal quality during radio traffic. Possible values are 0 for a poor link quality and 255 for a high link quality. For the localisation estimation of the mobile ZigBee node (MZN) the triangulation technique and RSS are used. To reduce the noise of the RSSI measurements an alpha-beta-filter (Penoyer 1993) with $\alpha=0.3$ and $\beta=0.1$ is used. Additionally the variable $n$ was optimised per link (single optimisation) and per direction (double optimisation). The test area is located in a park in Frankfurt am Main. The park is 7.4 hectare in size. Besides visitors there are natural obstacles like trees and bushes as well as artificial obstacles like walls, a playground and park benches. During the testing the following weather conditions were encountered: temperature of $5-6^{\circ} \mathrm{C}$, air pressure of $1032-1035 \mathrm{hPa}$, a relative humidity of 59 $\%$, no precipitation and a wind speed of $10 \mathrm{~km} / \mathrm{h}$ from the west. The distribution of the FZN is shown in figure 1 and marked as nodes. Some nodes are positioned in line-of-sight (LOS) to each other In addition, the LOS is randomly blocked by visitors in the park. The test itself consists of two parts where the first part includes distance measurements between all nodes measured 2000 times in an interval of $100 \mathrm{~ms}$. In the second part a MZN is carried through the area. The RSSI and LQI values are measured for all nodes every $100 \mathrm{~ms}$. While moving the node at marked positions, the current position is recorded. 


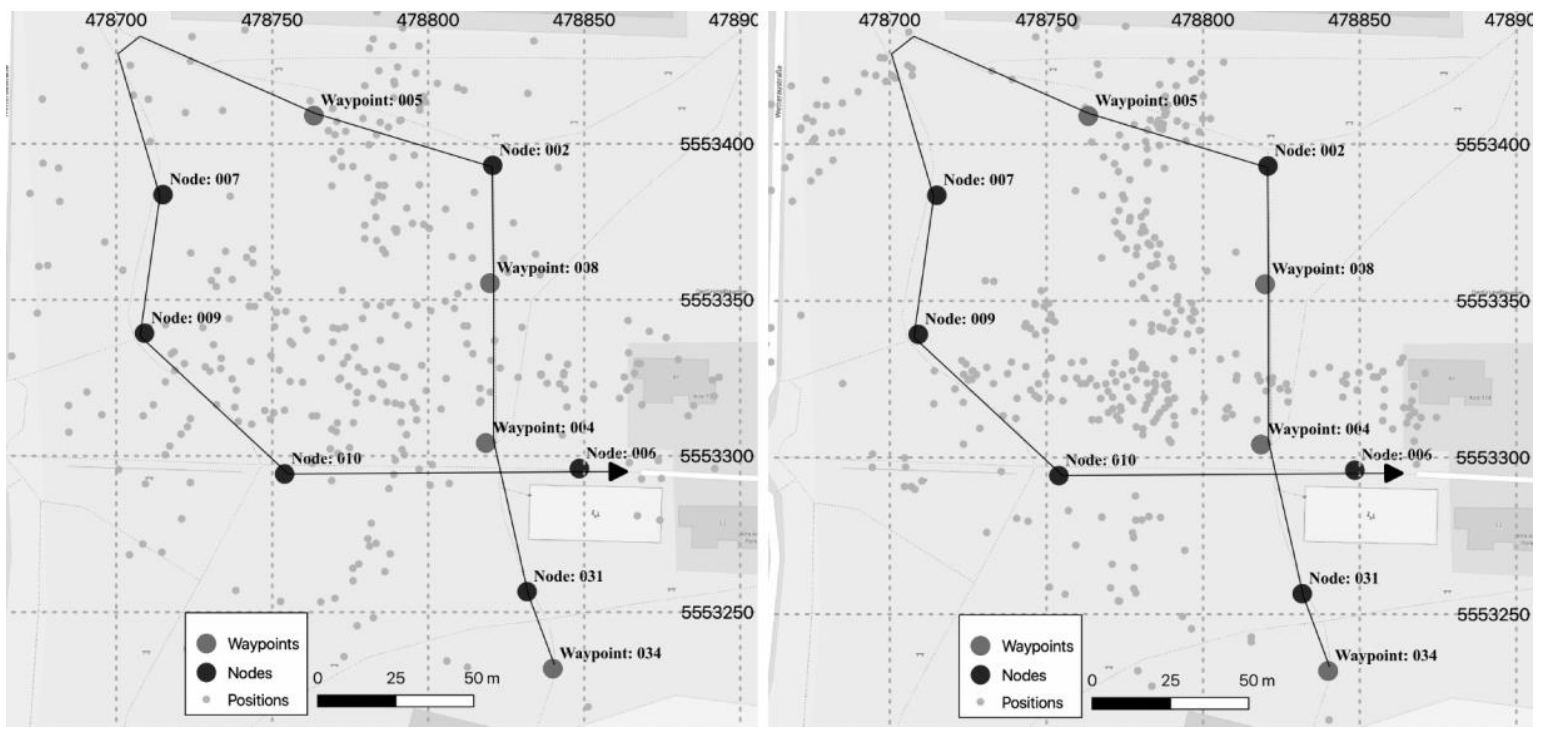

Figure 1. The resulted positions of the MZN in the test area calculated without (left) and with alpha-beta-filter (right)

\section{RESULTS}

The measurements in table 1 show that the distances between the nodes regarding coverage are not a problem. Even at the largest distance the LQI value remains high despite of the obstacles in the park. All connections are close to the maximal possible LQI value of 255 except of node 2 to 9 . Up to now no explanation for this difference could be found but the minimum value of $223.9 \mathrm{LQI}$ is not a quality problem. Table 2 shows that the RSSI variance between A and B nodes is small. However comparison between the calculated distances and the real distances reveals that some of the connections produce small and others huge variations. For example the connection between node 2 and 6 has only a deviation of $3.16 \%$ which is an absolute value of $3.19 \mathrm{~m}$ (table 2). Nevertheless some other connections deviate more than $50 \%$ like the connection between node 2 and 10 having a deviation of $57.14 \%$ which is an absolute value of $68.78 \mathrm{~m}$.

Table 1. Measured distances between the nodes based on different adjustments of the variable $n$

\begin{tabular}{|c|c|c|c|c|c|c|c|c|}
\hline $\begin{array}{l}\text { Node } \\
\text { A }\end{array}$ & $\begin{array}{l}\text { Node } \\
\text { B }\end{array}$ & $\begin{array}{l}\text { Distance } \\
\text { Real } \\
{[\mathrm{m}]} \\
\end{array}$ & $\begin{array}{l}\text { Distance } \\
\text { Measured } \\
{[\mathrm{m}]}\end{array}$ & $\begin{array}{l}\text { Distance } \\
\text { Single } \\
\text { Optimised } \\
{[\mathrm{m}]} \\
\end{array}$ & $\begin{array}{l}\text { Distance } \\
\text { Double } n \\
\text { Optimised } \\
{[\mathrm{m}]} \\
\end{array}$ & $\begin{array}{l}\text { Single } \mathrm{n} \\
\text { Optimised }\end{array}$ & $\begin{array}{l}\text { Double } \mathrm{n} \\
\text { Optimised }\end{array}$ & $\begin{array}{l}\text { Mean } \\
\text { LQI }\end{array}$ \\
\hline 2 & 6 & 100.98 & 104.17 & 104.17 & 104.17 & 2.10 & 2.10 & 252.00 \\
\hline 2 & 7 & 106.11 & 79.75 & 103.78 & 104.40 & 2.00 & 2.00 & 250.00 \\
\hline 2 & 9 & 138.97 & 220.49 & 127.67 & 127.82 & 2.30 & 2.30 & 223.90 \\
\hline 2 & 10 & 120.37 & 51.59 & 115.40 & 115.40 & 1.80 & 1.80 & 252.00 \\
\hline 2 & 31 & 136.95 & 217.97 & 126.34 & 126.31 & 2.30 & 2.30 & 247.07 \\
\hline 6 & 7 & 159.70 & 104.15 & 137.35 & 137.36 & 2.00 & 2.00 & 252.00 \\
\hline 6 & 9 & 145.97 & 88.28 & 155.34 & 155.42 & 1.90 & 1.90 & 248.89 \\
\hline 6 & 10 & 94.49 & 107.02 & 83.12 & 94.75 & 2.20 & 2.15 & 252.00 \\
\hline 6 & 31 & 42.84 & 59.99 & 38.90 & 43.08 & 2.30 & 2.25 & 252.01 \\
\hline 7 & 9 & 44.78 & 35.01 & 43.72 & 43.72 & 2.00 & 2.00 & 249.47 \\
\hline 7 & 10 & 97.58 & 40.59 & 87.24 & 102.31 & 1.80 & 1.75 & 252.00 \\
\hline 7 & 31 & 172.56 & 94.94 & 168.33 & 168.47 & 1.90 & 1.90 & 248.35 \\
\hline 9 & 10 & 63.62 & 48.83 & 62.00 & 62.11 & 2.00 & 2.00 & 248.23 \\
\hline 9 & 31 & 147.92 & 129.75 & 129.75 & 129.76 & 2.10 & 2.10 & 248.11 \\
\hline 10 & 31 & 86.35 & 45.67 & 74.97 & 86.96 & 1.90 & 1.85 & 252.02 \\
\hline
\end{tabular}


As described $n$ was adjusted per link based on the first 2000 measurements. Thus each route has an optimised $n$. The results show an improvement between the measured distances with $n=2.1$ and the distances with a single optimised $n$. In total a reduction of the deviation could be achieved. The mean deviation without improved $n$ was $35.90 \%$ and with single optimisation a mean deviation of $7.36 \%$ of the WMN was reached.

Table 2. Deviations of calculated distances between the nodes compared to the real distances

\begin{tabular}{|c|c|c|c|c|c|c|c|c|c|}
\hline $\begin{array}{l}\text { Node } \\
\text { A }\end{array}$ & $\begin{array}{l}\text { Node } \\
\text { B }\end{array}$ & $\begin{array}{l}\text { Deviation } \\
\text { Measured } \\
{[\%]}\end{array}$ & $\begin{array}{l}\text { Deviation } \\
\text { Single } \\
\text { Optimized } \\
{[\%]}\end{array}$ & $\begin{array}{l}\text { Deviation } \\
\text { Double n } \\
\text { Optimized } \\
{[\%]}\end{array}$ & $\begin{array}{l}\text { Deviation } \\
\text { Measured } \\
{[\mathrm{m}]}\end{array}$ & $\begin{array}{l}\text { Deviation } \\
\text { Single } \\
\text { Optimized } \\
{[\mathrm{m}]}\end{array}$ & $\begin{array}{l}\text { Deviation } \\
\text { Double n } \\
\text { Optimized } \\
{[\mathrm{m}]}\end{array}$ & $\begin{array}{l}\text { Mean } \\
\text { RSSI } \\
{[\mathrm{dBm}]}\end{array}$ & $\begin{array}{l}\text { Variance } \\
\text { RSSI } \\
{[\mathrm{dBm}]}\end{array}$ \\
\hline 2 & 6 & 3.16 & 3.16 & 3.16 & 3.19 & 3.19 & 3.19 & -79.41 & 1.05 \\
\hline 2 & 7 & 24.84 & 2.20 & 1.62 & 26.36 & 2.33 & 1.72 & -76.97 & 1.14 \\
\hline 2 & 9 & 58.66 & 8.13 & 8.02 & 81.53 & 11.30 & 11.15 & -86.25 & 1.66 \\
\hline 2 & 10 & 57.14 & 4.12 & 4.12 & 68.78 & 4.96 & 4.96 & -73.00 & 0.12 \\
\hline 2 & 31 & 59.16 & 7.75 & 7.73 & 81.02 & 10.61 & 10.58 & -86.14 & 5.44 \\
\hline 6 & 7 & 34.78 & 13.99 & 13.99 & 55.55 & 22.35 & 22.35 & -79.41 & 0.56 \\
\hline 6 & 9 & 39.52 & 6.42 & 6.47 & 57.69 & 9.37 & 9.45 & -77.90 & 1.00 \\
\hline 6 & 10 & 13.26 & 12.04 & 0.27 & 12.53 & 11.37 & 0.25 & -79.66 & 2.26 \\
\hline 6 & 31 & 40.04 & 9.2 & 0.55 & 17.15 & 3.94 & 0.24 & -74.38 & 1.10 \\
\hline 7 & 9 & 21.82 & 2.38 & 2.38 & 9.77 & 1.06 & 1.06 & -69.47 & 0.72 \\
\hline 7 & 10 & 58.41 & 10.59 & 4.86 & 56.99 & 10.34 & 4.74 & -70.81 & 0.56 \\
\hline 7 & 31 & 44.98 & 2.45 & 2.37 & 77.62 & 4.22 & 4.09 & -78.56 & 0.48 \\
\hline 9 & 10 & 23.25 & 2.55 & 2.38 & 14.79 & 1.62 & 1.52 & -72.50 & 7.77 \\
\hline 9 & 31 & 12.28 & 12.28 & 12.28 & 18.16 & 18.16 & 18.16 & -81.41 & 1.40 \\
\hline 10 & 31 & 47.12 & 13.18 & 0.71 & 40.69 & 11.38 & 0.61 & -71.89 & 0.41 \\
\hline
\end{tabular}

The tables (1-2) show the percentage and absolute improvement of a measurement where $n$ is the average between the $n$ s of the two directions of a link. With this method the mean deviation was reduced to $4.73 \%$ in the WMN. The differences between the fixed $n$ and the two optimisation steps are shown in figure $2 \mathrm{a}$. In the experiment of the localisation estimation of the moving MZN a peak can be seen in figure $2 \mathrm{~b}$ when the MZN is passing the position of a FZN.
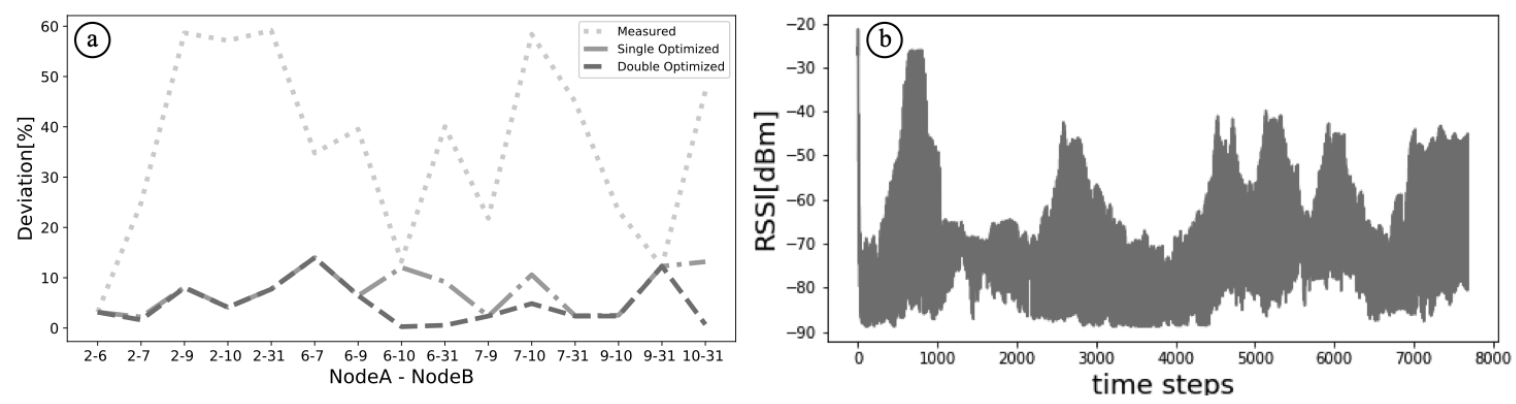

Figure 2. a) Deviations of distance calculation of different $n$. b) RSSI values recorded by the MZN towards all FZN

Figure 1 shows the positions of the MZN with and without the use of an alpha-beta-filter. It can be seen that the waypoints with the alpha-beta-filter are condensed but have an overall drift to the left side.

\section{CONCLUSION}

It is promising that the results can still be improved by optimising $n$ not only in respect to the link between the individual nodes but also in respect to the direction. The nodes are suitable for this type of application due to their design and cost. Further optimisations for the piecewise distribution of the nodes using correction algorithms and additional sensors should be the next step. 


\section{REFERENCES}

Al-Ammar, M.A. et al, 2014, Comparative survey of indoor positioning technologies, techniques, and algorithms. In IEEE Cyberworlds International Conference. Santander, Spain, pp. 245-252.

Altay, N. \& Green III, W. G., 2006. OR/MS research in disaster operations management. European journal of operational research, Vol. 175, No. 1, pp 475-493.

Dreyer, R., 2012. Sportküstenschifferschein \& Sportbootführerschein See. Delius Klasing, Bielefeld, Germany.

Groves, P. D., 2013. Principles of GNSS, inertial, and multisensor integrated navigation systems. Artech House Publishers, Boston, USA, London, GB.

Jachs, S., 2011. Einführung in das Katastrophenmanagement. tredition, Hamburg, Germany.

Krauße, M. and Konrad, R., 2014. Drahtlose ZigBee-Netzwerke: Ein Kompendium. Springer-Verlag, Wiesbaden, Germany. Liu, H., Darabi, H., Banerjee, P. \& Liu, J., 2007. Survey of wireless indoor positioning techniques and systems. In IEEE Transactions on Systems, Man, and Cybernetics, Part C (Applications and Reviews), Vol. 37, No.6, pp 1067-1080

Penoyer, R., 1993. The alpha-beta filter, C User's Journal, Vol. 11, No. 7, pp 73-86.

Rappaport, T. S., 2002. Wireless communications-principles and practice. Microwave Journal, Vol. 45, No. 12, pp $128-129$.

Tariq, Z. B. et al, 2017. Non-gps positioning systems: a survey. ACM Computing Surveys (CSUR), Vol. 50, No. 4, p 57.

ZigBee Standards Organisation 2012, Zigbee specification (document 05344r20) 